\title{
Participation in delivery system reform programs and U.S. acute care hospital integration into behavioral health
}

\author{
Larry R. Hearld ${ }^{1}$, Reena J. Kelly ${ }^{2}$ \\ ${ }^{1}$ Department of Health Services Administration, School of Health Professions, University of Alabama at Birmingham, Birmingham, Alabama, USA; \\ ${ }^{2}$ Department of Healthcare Administration and Policy, School of Health Sciences, University of New Haven, West Haven, CT, USA \\ Contributions: (I) Conception and design: LR Hearld; (II) Administrative support: RJ Kelly; (III) Provision of study materials or patients: LR Hearld; \\ (IV) Collection and assembly of data: LR Hearld; (V) Data analysis and interpretation: Both authors; (VI) Manuscript writing: Both authors; (VII) \\ Final approval of manuscript: Both authors. \\ Correspondence to: Larry R. Hearld, PhD. Department of Health Services Administration, School of Health Professions, University of Alabama at \\ Birmingham, SHPB 559, $17202^{\text {nd }}$ Ave South, Birmingham, Alabama, USA. Email: lhearld@uab.edu.
}

Background: Growing recognition of the prevalence and consequences of behavioral health disorders has reinvigorated efforts to transform how behavioral health is delivered, especially amongst acute care hospitals, and stimulated discussions about the ways to support these efforts. The purpose of this study was to examine the relationship between hospital participation in two delivery system reform programs-Accountable Care Organizations (ACO) and medical homes—and behavioral health integration among United States' acute care hospitals.

Methods: The study used a pooled, cross-sectional analysis with the hospital as the unit of observation. Our primary analysis utilized a negative binomial regression model to examine the relationship between hospital participation in delivery system reform programs and the breadth of behavioral health integration. Our secondary analysis used four binary logistic regression models to assess whether participation in delivery system reform programs was associated with behavioral health integration in specific areas of the hospital.

Results: On average, hospitals that were only participating in an Accountable Care Organization reported 1.09 times more behavioral health integration areas, relative to hospitals that were not participating in any delivery system reform programs ( $\mathrm{IRR}=1.09, \mathrm{P}<0.05)$. Similarly, hospitals with an established medical home program reported 1.21 times more behavioral health integration areas, on average, relative to hospitals that were not participating in any delivery system reform programs (IRR $=1.21, \mathrm{P}<0.001)$. Hospitals that were participating in both an Accountable Care Organization and had an established medical home program reported 1.31 times more behavioral health integration areas, relative to hospitals with neither (IRR $=1.31$, $\mathrm{P}<0.001)$.

Conclusions: Our analysis indicates that participation in either an Accountable Care Organization or medical home program, by itself, may be sufficient to support behavioral health integration, however, having an established medical home program may stimulate more robust integration than Accountable Care Organization participation. Likewise, hospitals participating in both programs may promote even greater behavioral health integration than single program participation. Collectively, our findings highlight opportunities to improve behavioral and physical health integration by U.S. acute care hospitals.

Keywords: Acute care hospitals; Accountable Care Organizations (ACO); medical home, behavioral health integration

Received: 22 June 2021; Accepted: 09 September 2021; Published: 25 June 2022.

doi: $10.21037 /$ jhmhp-21-45

View this article at: https://dx.doi.org/10.21037/jhmhp-21-45 


\section{Introduction}

It has been estimated that nearly $20 \%$ of people globally have experienced a mental disorder (1) and half of all people in the United States will be diagnosed with a behavioral health disorder, defined as a diagnosis for a mental health or substance use disorder, in their lifetime (2). Growing recognition of the prevalence and consequences of behavioral health disorders has led to calls to rethink how behavioral health is delivered $(3,4)$. The need for such changes is especially salient amongst acute care hospitals. In 2014, behavioral health diagnoses ranked as the third most common reason for visiting an emergency department (ED) in the United States and the seventh most common reason for acute care hospitalizations $(5,6)$. Moreover, the use of acute care hospitals for behavioral health issues is on the rise, with emergency department visits and acute care inpatient hospitalization rates for patients with a behavioral health disorder diagnosis increasing 48.1 and 23.2 percent, respectively, between 2005/2006 and $2014(5,6)$. Patients with behavioral health disorders also present more challenging cases for acute care hospitals and consume more resources, with studies showing that ED visits and acute care hospitalizations of patients with a behavioral health diagnosis were 1.2 hours and 4.4 days longer, respectively, than patients without such a diagnosis $(7,8)$.

Behavioral health experts increasingly advocate for integration between physical and behavioral health care to counteract these trends and improve the quality of behavioral health care $(4,9,10)$. The Agency for Healthcare Research and Quality (AHRQ) defines integration as the systematic communication and coordination across behavioral and medical care providers (11). Studies have found that integrating primary and behavioral health care can improve access to services, improve outcomes for patients with conditions such as diabetes, cholesterol, and hypertension, and reduce hospital admissions and their associated costs $(12,13)$.

Despite these benefits, health care delivery organizations face a number of challenges to integrating physical and behavioral health services. One evaluation of the integration of primary care into community behavioral health agencies, for example, found that these organizations struggled to recruit and retain qualified staff, secure adequate physical space, and share patient data between primary care and behavioral health providers (10). Moreover, to date most studies have focused on integrating behavioral health into primary care settings (e.g., primary care physician offices).
Given the aforementioned growth in behavioral health services provided by acute care hospitals, an important question is how to support efforts by acute care hospitals to integrate behavioral health care.

Delivery system reform models in the United States have been suggested as one means of supporting the integration of behavioral and medical care (14). Accountable Care Organizations (ACO) and medical homes, in particular, have been highlighted as having the potential to support behavioral health and physical care integration due to their whole-person approach to delivering care (14-16). An ACO is an organization that is formed for the purpose of managing the full continuum of care and assuming responsibility for the overall costs and quality of care for a defined population $(17,18)$. The medical home attempts to transform the delivery of care through the adoption of the core principles of primary care (first-contact care that is comprehensive and coordinated across the care continuum), team-based care (using the full talents of a range of clinical professions), and patient-centered care (patient input into care decisions) by health care provider organizations, often primary care providers. Some experts have argued that these delivery system models are complementary and may offer synergies that neither alone can provide (18). For example, ACOs may be most successful when they are associated with a strong primary care foundation. Similarly, although the medical home encourages providers to take responsibility for providing and/or coordinating care, these providers may not have direct control or influence over other providers that can affect the cost and quality of care.

Despite their potential, empirical research is lacking on whether these reforms are, in fact, associated with greater efforts to integrate behavioral health into existing care activities. Given these gaps in the literature, the purpose of this study was to: (I) describe the extent to which acute care hospitals have integrated behavioral health into their existing service activities; and (II) describe the relationship between delivery system reforms and behavioral health integration by U.S. acute care hospitals. Study findings will provide important descriptive information for policy makers, practitioners, and patients who would like to understand current efforts by hospitals to integrate behavioral health activities and the potential impact of delivery system policies on these efforts.

\section{Breadth of behavioral bealth integration}

Hospitals have a number of opportunities to pursue 
behavioral health integration given the range of services provided and conditions treated. For example, hospitals may have dedicated inpatient psychiatric units and, as noted earlier, many hospitals treat patients with a behavioral health diagnosis in the emergency department. Likewise, hospitals increasingly own physician practices (19-21) where a majority of behavioral health care is provided for conditions such as depression (22). Hospitals that pursue behavioral health integration in more of these areas arguably are better positioned to address the myriad behavioral health conditions and settings where patients seek care for these conditions. Thus, our primary focus in this study was the breadth of behavioral health integration, which we define as the number of different service areas that a hospital has routinely integrated behavioral health services.

\section{Accountable care organizations (ACOs)}

ACOs are an approach to aligning efforts across the care delivery continuum by creating accountability for a defined patient population $(18,23)$. ACOs consist of different provider configurations (integrated delivery systems, hospital-based systems; virtual networks of physicians) to deliver care $(24,25)$, which are designed, in part, to foster coordination of care activities between these different providers. Additionally, ACOs modify traditional fee-forservice reimbursement methods by incorporating shared savings arrangements, which allow ACO providers to share in the savings when the costs of care for the ACO population are below historical benchmarks (26).

Behavioral health disorders are among the most expensive conditions to treat, ranking second to only cardiovascular conditions in per capita spending as a primary diagnosis (27). Moreover, behavioral health disorders add substantial costs when they co-occur with other medical conditions (28). More effectively and efficiently managing these high-cost patients through the integration of medical and behavioral health services would ostensibly be a high priority for hospitals that participate in an ACO because doing so could create cost savings to be shared by a hospital. Likewise, integration into more service areas would likely increase the number of opportunities to create these cost savings. Therefore, we hypothesize that: "H1: Relative to hospitals that are not participating in an ACO, hospitals that participate in an ACO will be associated with a greater breadth of behavioral bealth integration."

\section{Medical bome}

The medical home, often referred to as the patient-centered medical home, can be defined as a team-based health care delivery model that provides personalized, continuous, and integrated medical care with the goal of improving the health of people, families, and communities (29). The medical home is based on a number of core principles, including individualized care that incorporates shared goal setting, whole person orientation that includes physical and behavioral needs, coordinated care that addresses the multifaceted needs of patients, and enhanced access to services (30,31). A number of experts have argued that these principles overlap considerably with models of integrated behavioral health and have suggested that medical homes may be one approach to integrating medical and behavioral health $(30,32)$. That is, hospitals may use the medical home as a vehicle to integrate medical and behavioral health. Likewise, hospitals may learn from and leverage their experience with the medical home to integrate medical and behavioral health in other service areas. Consequently, we hypothesize that: "H2: Relative to hospitals without an established medical home program, hospitals with an established medical home program will be associated with a greater breadth of behavioral health integration."

\section{Complementary roles of ACos and medical homes}

ACOs and medical homes are argued to play complementary roles $(18,33)$. As noted above, ACOs attempt to integrate care and manage the health of a population across the full continuum of care (e.g., primary care, specialty care, acute care, long-term care, behavioral health) by creating financial accountability among the participating organizations (i.e., financial incentives/disincentives for meeting cost goals). Medical homes, on the other hand, are more limited in their scope and typically emphasize the transformation of how primary care is delivered. This often entails the coordination and integration of care between primary care, specialty care, and acute care, again facilitated by financial payments, however accountability is much more limited in scope (e.g., primary care services, no downside loss). Extensive research has demonstrated that an effective primary care delivery system can achieve significant cost savings $(34,35)$, which is why some have argued that ACOs, to be effective, may require a robust primary care infrastructure such as that provided by medical homes 
$(18,33)$. Thus, participation in an ACO and a medical home may provide complementary, even synergistic, incentives to integrate behavioral health into more service areas. That is, ACO participation may provide cost savings incentives to integrate behavioral health into more service areas, while participation in a medical home program may provide the means of accomplishing these cost savings. Consequently, we hypothesize that: "H3: Relative to hospitals that are participating in only an ACO or only have a medical home program, hospitals participating in an ACO and have an established medical home program will be associated with a greater breadth of behavioral health integration."

\section{Methods}

\section{Data sources}

The data for this study were drawn from three sources: (I) the American Hospital Association's (AHA) Annual Survey of Hospitals (years 2017-2019); (II) the Health Resources and Services Administration's Area Health Resource File (AHRF; years 2017-2019); and (III) County Health Rankings and Roadmaps data. The AHA Annual Survey of Hospitals is an annual electronic survey of approximately 6,300 hospitals in the United States and provides extensive data regarding hospital organizational characteristics (36). The AHA reports an $80 \%$ response rate to this survey each year. The AHRF is a collection of data from different sources (e.g., Census Bureau, Bureau of Labor Statistics) that is used to construct the environmental characteristics considered in the study. The County Health Rankings and Roadmaps data is a collaboration between the Robert Wood Johnson Foundation and the University of Wisconsin Population Health Institute that was developed to provide insights into how local community factors may influence health (37). These data sources were merged together for each year and then combined to create a pooled, crosssectional data set for analysis. The study received ethical approval (determined to be Not Human Subjects Research) by the Institutional Review Board of the University of Alabama at Birmingham (Protocol \#: 300003568).

\section{Dependent variables}

Beginning in 2017, the AHA Annual Survey included a question that asked whether a hospital routinely integrates behavioral health services in one or more of the four following areas: (I) emergency services; (II) primary care services; (III) acute inpatient care; and (IV) extended care (i.e., care for individuals who do not require acute care such as that provided in a hospital but who need more care than can be given at home (e.g., skilled nursing facilities, nursing homes). The survey defined integration as ranging from colocated medical and behavioral health providers, with some screening and treatment planning, to fully integrated care where medical and behavioral health providers function as a team in shared practice. The primary analysis focused on the extent to which hospitals integrated behavioral health services and was operationalized as the sum across these four areas (range, 0 to 4). A secondary analysis examined each of these areas independently as dichotomous variables $(1=$ Yes; $0=$ No).

\section{Independent variables}

Our primary interest was in hospital participation in delivery system reform programs, which we measured with four mutually exclusive dichotomous variables. One variable reflected whether a hospital was a member of an ACO but did not have an established medical home program ( 1 = Yes; $0=$ No). A second variable reflected whether a hospital had established a medical home program but was not a member of an ACO $(1=$ Yes; $0=$ No). Our third variable reflected whether a hospital was both a member of an ACO and had established a medical home program $(1=$ Yes; $0=$ No). Finally, our fourth variable reflected hospitals that did not participate in either program $(1=$ Yes; $0=$ No) and served as the referent group.

The analysis also controlled for a number of hospital organizational characteristics that previous research has found associated with participation in delivery system reform programs (38) as well the physical, socioeconomic, and health delivery system characteristics of the surrounding community. Table 1 provides a list of these variables and how they were operationalized.

\section{Statistical analysis}

The unit of analysis was the hospital. Univariate statistics were used to describe the sample hospitals, including their overall level of behavioral health integration as well as integration in individual areas. Our primary analysis utilized a negative binomial regression model to examine the relationship between hospital participation in delivery system reform programs and the breadth of behavioral 
Table 1 Study variable operationalizations

\begin{tabular}{|c|c|}
\hline Variable & Operationalization \\
\hline \multicolumn{2}{|c|}{ Behavioral health integration activities } \\
\hline Acute inpatient & $\begin{array}{l}1=\text { hospital has integrated behavioral health in acute inpatient service area; } 0=\text { hospital has not integrated } \\
\text { behavioral health in acute inpatient service area }\end{array}$ \\
\hline Primary care & $\begin{array}{l}1=\text { hospital has integrated behavioral health in primary care service area; } 0=\text { hospital has not integrated } \\
\text { behavioral health in primary care service area }\end{array}$ \\
\hline Extended care & $\begin{array}{l}1=\text { hospital has integrated behavioral health in extended care service area; } 0=\text { hospital has not integrated } \\
\text { behavioral health in extended care service area }\end{array}$ \\
\hline $\begin{array}{l}\text { Count of behavioral health } \\
\text { integration activities }\end{array}$ & $\begin{array}{l}\text { Sum of four types of behavioral health integration (acute inpatient, primary care, emergency service, and } \\
\text { extended care integration) }\end{array}$ \\
\hline $\begin{array}{l}\text { Medical Home } \\
\text { Participation }\end{array}$ & $\begin{array}{l}1=\text { hospital has an established medical home program; } 0=\text { hospital does not have an established medical } \\
\text { home program }\end{array}$ \\
\hline Both & $1=$ hospital participated in both $\mathrm{ACO}$ and has an established medical home program \\
\hline \multicolumn{2}{|l|}{ Organizational controls } \\
\hline Ownership & $\begin{array}{l}\text { Three dummy variables representing private not-for-profit hospitals, public/government not-for-profit } \\
\text { hospitals, and for-profit hospitals (referent) }\end{array}$ \\
\hline System affiliation & $1=$ member of system; $0=$ independent hospital \\
\hline Teaching status & $\begin{array}{l}\text { 1= either having a residency training approval by Accreditation Council for Graduate Medical Education, } \\
\text { medical school affiliation reported to American Medical Association, member of Council of Teaching } \\
\text { Hospital of the Association of American Medical Colleges, or residency approved by the American } \\
\text { Osteopathic Association; } 0=\text { not a teaching hospital }\end{array}$ \\
\hline $\begin{array}{l}\text { Clinically integrated } \\
\text { network }\end{array}$ & $\begin{array}{l}\text { A collection of healthcare providers, such as physicians, hospitals, and post-acute care treatment providers, } \\
\text { that come together to improve patient care and reduce overall healthcare costs. Clinically integrated } \\
\text { networks rely on evidence-based care guidelines to provide high-quality care across participating providers }\end{array}$ \\
\hline $\begin{array}{l}\% \text { of patient revenue from } \\
\text { capitation }\end{array}$ & Total revenue from patients with capitated contracts/total patient revenue \\
\hline Size & $\begin{array}{l}\text { Four dummy variables representing the following hospitals: } 1-99 \text { beds (referent); } 100-299 \text { beds; } \\
300-499 \text { beds; } 400 \text { or more beds }\end{array}$ \\
\hline \multicolumn{2}{|l|}{ Community controls } \\
\hline Geographic location & $\begin{array}{l}\text { Three dummy variables representing the geographic location of the hospital: urban (referent); suburban; and } \\
\text { rural }\end{array}$ \\
\hline $\begin{array}{l}\text { Medicare managed care } \\
\text { penetration }\end{array}$ & $\begin{array}{l}\text { Number of Medicare beneficiaries in a county enrolled in a Medicare managed care plan / Total number of } \\
\text { Medicare eligible beneficiaries in a county }\end{array}$ \\
\hline Percent minority & Percentage of county residents that were non-white \\
\hline
\end{tabular}

Table 1 (continued) 
Table 1 (continued)

\begin{tabular}{ll}
\hline Variable & Operationalization \\
\hline Percent over 65 & Percentage of county residents 65 and older \\
Percent over 65 & Percentage of county residents $200 \%$ or more below the federal poverty level \\
Herfindahl-Hirschman & $\begin{array}{l}\text { Sum of square of hospital market share in a hospital service area (HSA), based on number of licensed beds } \\
\text { index }\end{array}$ \\
set up and staffed for use & $\begin{array}{l}\text { Three dummy variables indicating whether the county had a shortage of mental health professionals: county } \\
\text { not an MH HPSA (referent); partial county is MH HPSA; whole county is MH HPSA }\end{array}$ \\
Community health status & $\begin{array}{l}\text { Composite index (z-score) of } 16 \text { items across four domains: clinical care (diabetic monitoring, preventable } \\
\text { hospital stays, access of primary care physicians), health behaviors (adult smoking, adult obesity, excessive } \\
\text { drinking, teen births, motor vehicle crash deaths), social and economic factors (children in poverty, social } \\
\text { associations, unemployment, violent crimes), and the physical environment (air pollution, severe housing } \\
\text { problems, limited access to healthy foods). Higher scores indicate worse health status. Data source: County } \\
\text { Health Rankings and Roadmaps data }\end{array}$ \\
\hline
\end{tabular}

ACO, accountable care organization; MH HPSA, mental health professional shortage area.

health integration. Our secondary analysis used four binary logistic regression models to assess whether participation in delivery system reform programs was associated with behavioral health integration in specific areas of the hospital. Relationships in the primary analysis (negative binomial) were considered statistically significant using a $95 \%$ confidence interval. Statistical significance in the secondary (binary logistic) models was adjusted to account for multiple comparisons using a $99 \%$ confidence interval.

\section{Results}

\section{Sample descriptives}

On average, sample hospitals had integrated into less than half of the possible behavioral health areas in 2017 (mean 1.6, SD 1.5). The number of areas of behavioral health integration increased slightly although significantly to 1.8 areas (SD 1.5) by $2019(\mathrm{t}=5.8, \mathrm{P}<0.001)$. Behavioral health integration was most prevalent in the emergency room, with $58.2 \%$ and $65.0 \%$ of the sample hospitals reporting integration in this area in 2017 and 2019, respectively. Behavioral health integration was least prevalent in extended care, with only $16.5 \%$ and $17.6 \%$ of the sample hospitals in 2017 and 2019, respectively, reporting integration in this area. Notably, this was the only area that did not experience a significant increase in the number of hospitals reporting integration over the study period $\left(\chi^{2}=1.3, \mathrm{P}=0.26\right)$.

More than half $(56.1 \%$ in 2017 and $60.9 \%$ in 2019) of the sample hospitals were not participating in an ACO and also did not have an established medical home program (Table 2). Nearly $13 \%$ of the sample hospitals were participating in an ACO only in 2017, but this percentage decreased by over half to $6.0 \%$ in 2019 . A similar percentage (11.6\%) of sample hospitals reported having an established medical home program but not participating in an ACO in 2017, but this percentage increased to $17.3 \%$ in 2019 . Nearly one-fifth (19.8\%) of the sample hospitals reported participating in an ACO and having an established medical home program in 2017. This percentage declined slightly to $15.8 \%$ by 2019 . Additional sample characteristics, organized by behavioral health integration areas and delivery system reform programs, are provided in Tables S1,S2.

\section{Breadth of behavioral health integration}

On average, hospitals that were participating in an ACO only reported 1.09 times more behavioral health integration areas, relative to hospitals that were not participating in any delivery system reform programs (IRR $=1.09, \mathrm{P}<0.05$; Table 3). Similarly, hospitals with an established medical home program reported 1.21 times more behavioral health integration areas, on average, relative to hospitals that were not participating in any delivery system reform programs (IRR $=1.21, \mathrm{P}<0.001)$. Hospitals that were participating in both an ACO and had an established medical home program reported 1.31 times more behavioral health integration areas, relative to hospitals with neither (IRR $=1.31, \mathrm{P}<0.001)$. 
Table 2 Sample characteristics by year

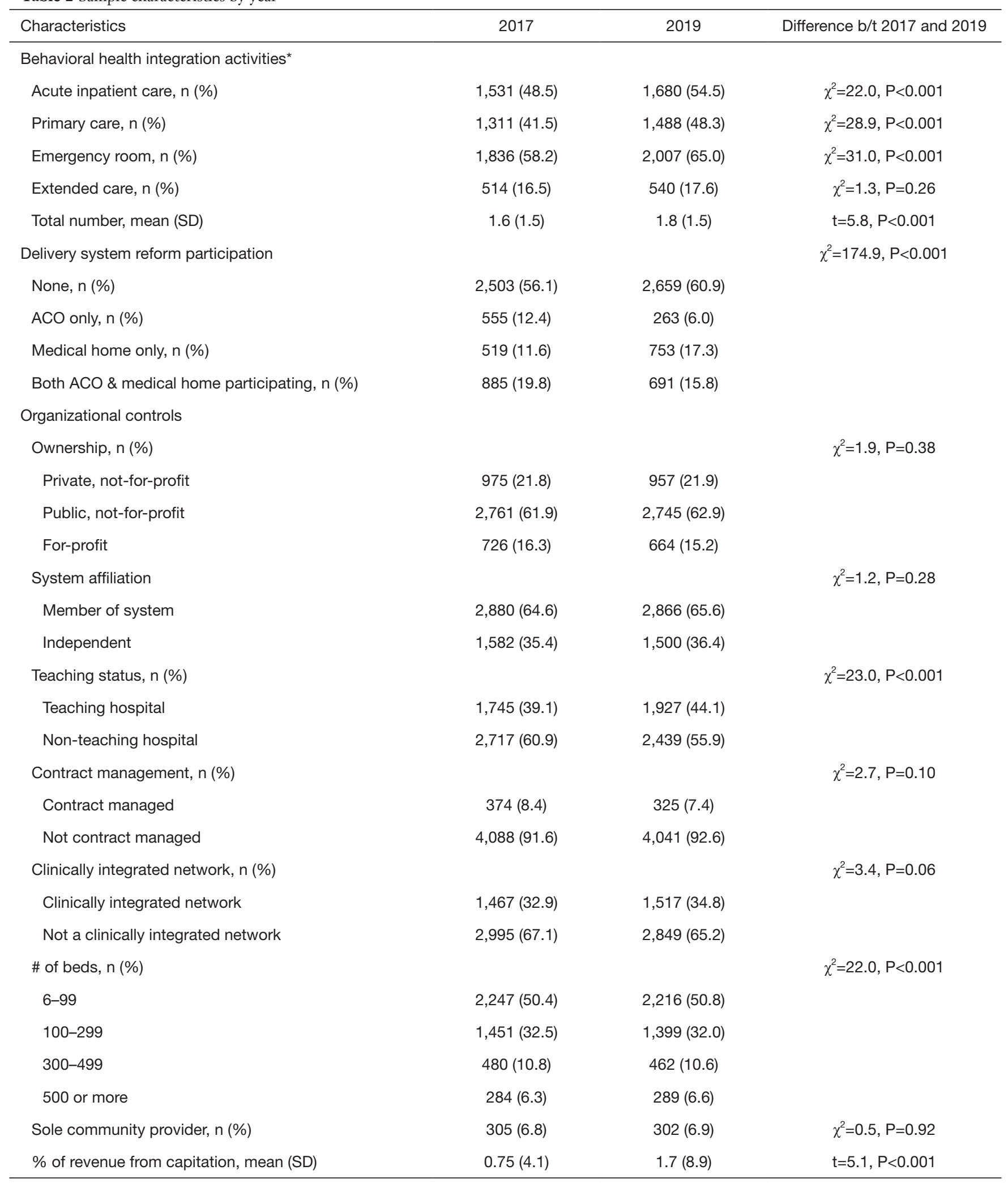

Table 2 (continued) 
Table 2 (continued)

\begin{tabular}{|c|c|c|c|}
\hline Characteristics & 2017 & 2019 & Difference b/t 2017 and 2019 \\
\hline Geographic location, n (\%) & & & $\chi^{2}=0.02, P=0.99$ \\
\hline Rural hospital & $815(18.3)$ & $801(18.3)$ & \\
\hline Suburban & $1,039(23.3)$ & $1,011(23.2)$ & \\
\hline Medicare managed care penetration, mean (SD) & $28.9(15.6)$ & $30.0(14.6)$ & $\mathrm{t}=3.4, \mathrm{P}<0.001$ \\
\hline Percent minority, mean (SD) & $18.7(15.7)$ & $18.9(15.8)$ & $t=0.4, P=0.65$ \\
\hline Percent over 65, mean (SD) & $17.3(4.4)$ & $17.8(4.5)$ & $t=4.6, P<0.001$ \\
\hline Percent below federal poverty level, mean (SD) & $14.4(5.4)$ & $14.2(5.3)$ & $t=2.2, P=0.02$ \\
\hline County not MH HPSA & $293(6.6)$ & $237(5.4)$ & \\
\hline Partial county is MH HPSA & $2,037(45.7)$ & $1,867(42.8)$ & \\
\hline Whole county is MH HPSA & $2,130(47.8)$ & $2,260(51.8)$ & \\
\hline Health status of community & $0.002(0.5)$ & $-0.002(0.5)$ & $\mathrm{t}=0.42, \mathrm{P}=0.67$ \\
\hline $\mathrm{N}$ & 4,460 & 4,364 & \\
\hline
\end{tabular}

*, number of hospitals not reporting (i.e., missing values): acute inpatient care $(n=1,282)$; primary care $(n=1,286)$; emergency room $(n=1,279)$; extended care $(n=1,300)$. ACO, accountable care organization; MH HPSA, mental health professional shortage area.

There were also several significant relationships between the control variables and the breadth of behavioral health integration areas. Relative to for-profit hospitals, private not-for-profit hospitals and public, government hospitals reported 1.25 (95\% CI: 1.08, 1.45) and 1.35 (95\% CI: 1.19, 1.53) times more areas of integration. Teaching hospitals reported 1.12 times more areas of integration compared to non-teaching hospitals (95\% CI: 1.05, 1.18). Hospitals that were sole community providers reported 1.20 times more areas of integration (95\% CI: 1.06, 1.35). Larger hospitals were associated with more integration areas. For example, relative to hospitals with fewer than 100 beds, hospitals with 500 or more beds reported 1.71 times more integration areas (95\% CI: 1.54, 1.89). In general, the community level control variables were not significantly associated with the number of behavioral health integration areas. One notable exception was geographic location, where rural hospitals (IRR $=0.86,95 \%$ CI: $0.75,0.99)$ and suburban hospitals (IRR $=0.90,95 \%$ CI: $0.81,0.99)$ were associated with fewer areas of integration than urban hospitals. In the following sections, we discuss the relationships between delivery system reform participation and the individual areas of behavioral health integration.

\section{Acute care behavioral health integration}

On average, the odds of integrating behavioral health in acute care were 1.35 (99\% CI: 1.06, 1.73) times greater for hospitals with an established medical home program only, respectively, relative to hospitals that were not participating in either. Likewise, the odds of integrating behavioral health in acute care were 1.91 (99\% CI: 1.44, 2.54) times greater for hospitals that were both members of an ACO and had an established medical home program, relative to hospitals that were not participating in either an ACO or medical home (Table 3).

\section{Primary care behavioral health integration}

On average, the odds of integrating behavioral health in primary care were 1.83 (99\% CI: $1.44,2.33$ ) times greater for hospitals that had an established medical 
Table 3 Delivery system reform participation and behavioral health integration

\begin{tabular}{|c|c|c|c|c|c|}
\hline Variable & $\begin{array}{l}\text { Number of areas, } \\
\text { IRR }(95 \% \mathrm{Cl})^{1}\end{array}$ & $\begin{array}{l}\text { Acute inpatient, } \\
\text { OR }(99 \% \mathrm{Cl})^{2}\end{array}$ & $\begin{array}{l}\text { Primary care, } \\
\text { OR }(99 \% \text { Cl })^{2}\end{array}$ & $\begin{array}{l}\text { Emergency services, } \\
\text { OR }(99 \% \mathrm{Cl})^{2}\end{array}$ & $\begin{array}{l}\text { Extended services, } \\
\qquad \text { OR }(99 \% \mathrm{Cl})^{2}\end{array}$ \\
\hline \multicolumn{6}{|l|}{ Delivery system reform innovations } \\
\hline ACO only & $1.09(1.01,1.19)^{\star}$ & $1.32(0.98,1.78)^{\star}$ & $1.15(0.87,1.52)$ & $1.19(0.89,1.59)$ & $0.82(0.57,1.17)$ \\
\hline Medical Home only & $1.21(1.13,1.30)^{\star \star \star}$ & $1.35(1.06,1.73)^{\star \star}$ & $1.83(1.44,2.33)^{\star \star *}$ & $1.23(0.95,1.59)^{\star}$ & $1.33(0.96,1.84)^{*}$ \\
\hline \multicolumn{6}{|l|}{ Organizational controls } \\
\hline \multicolumn{6}{|l|}{ Ownership } \\
\hline For-profit & Referent & Referent & Referent & Referent & Referent \\
\hline Teaching & $1.12(1.05,1.18)^{\star \star \star}$ & $1.36(1.07,1.73)^{\star \star \star}$ & $1.34(1.06,1.70)^{\star \star *}$ & $1.32(1.04,1.68)^{\star \star}$ & $1.16(0.85,1.58)$ \\
\hline Contract managed & $1.00(0.90,1.12)$ & $0.86(0.61,1.21)$ & $0.89(0.65,1.23)$ & $1.10(0.80,1.52)$ & $1.36(0.89,2.07)$ \\
\hline Sole comm. provider & $1.20(1.06,1.35)^{\star \star}$ & $1.58(1.08,2.31)^{\star \star}$ & $1.20(0.82,1.76)$ & $1.66(1.13,2.44)^{\star \star \star}$ & $1.24(0.75,2.04)$ \\
\hline Clinically integrated & $1.11(1.04,1.18)^{\star \star \star}$ & $1.33(1.08,1.64)^{\star \star \star}$ & $1.16(0.94,1.43)$ & $1.36(1.10,1.68)^{\star \star \star}$ & $1.28(0.96,1.71)^{\star}$ \\
\hline \multicolumn{6}{|l|}{ \# of beds } \\
\hline 6-99 (referent) & Referent & Referent & Referent & Referent & Referent \\
\hline 100-299 & $1.37(1.26,1.48)^{\star \star \star}$ & $2.51(1.95,3.23)^{\star \star \star}$ & $1.30(1.00,1.69)^{\star \star}$ & $2.29(1.77,2.95)^{\star \star \star}$ & $1.63(1.14,2.34)^{\star \star \star}$ \\
\hline $300-499$ & $1.46(1.33,1.61)^{\star \star \star}$ & $3.11(2.11,4.57)^{\star \star \star}$ & $1.59(1.09,2.32)^{\star \star \star}$ & $2.77(1.85,4.16)^{\star \star \star}$ & $2.04(1.22,3.42)^{\star \star \star}$ \\
\hline
\end{tabular}

Community controls

Geographic location

Urban hospital

Referent

Referent

Referent

Referent

Referent

Suburban hospital

Rural hospital

$0.90(0.81,0.99)^{\star} \quad 0.77(0.55,1.07)^{\star}$

$0.81(0.58,1.13)$

$0.78(0.56,1.08)^{*}$

$0.97(0.63,1.50)$

$0.86(0.75,0.99)^{\star} \quad 0.65(0.43,0.98)^{\star \star}$

$0.85(0.56,1.30)$

$0.75(0.50,1.11)$

$0.92(0.53,1.58)$

Medicare MCO penetration

$0.99(0.99,1.00) \quad 0.99(0.98,1.00)^{\star}$

$0.99(0.98,1.00)$

$0.99(0.98,0.99)^{*}$

$1.00(0.99,1.01)$

Percent minority

$0.99(0.99,1.00) \quad 1.00(0.99,1.01)$

$0.99(0.98,0.99)^{\star *}$

$1.00(0.99,1.01)$

$0.99(0.98,1.01)$

Percent over 65

$0.99(0.99,1.01)$

$0.99(0.96,1.02)$

$1.01(0.97,1.04)$

$0.98(0.95,1.02)$

$1.01(0.96,1.03)$

Percent below poverty

$0.99(0.98,1.00)$

$0.99(0.96,1.04)$

$1.01(0.98,1.05)$

$0.97(0.94,1.01)$

$0.98(0.94,1.03)$

$1.02(0.90,1.14) \quad 0.92(0.57,1.49)$

$0.73(0.46,1.17)$

$1.41(0.90,2.21)^{*}$

$1.52(0.87,2.65)$

Mental Health HPSA

County not MH HPSA

Referent

Referent

Referent

Referent

Referent

Partial county is MH HPSA

$0.92(0.82,1.04) \quad 0.72(0.46,1.13)$

$0.93(0.59,1.47)$

$0.76(0.47,1.23)$

$1.09(0.61,1.96)$

Whole county is MH HPSA

$1.02(0.92,1.14) \quad 0.92(0.62,1.47) \quad 1.12(0.72,1.76) \quad 1.00(0.62,1.62)$

$1.17(0.66,2.09)$

Table 3 (continued) 
Table 3 (continued)

\begin{tabular}{|c|c|c|c|c|c|}
\hline Variable & $\begin{array}{l}\text { Number of areas, } \\
\text { IRR }(95 \% \mathrm{Cl})^{1}\end{array}$ & $\begin{array}{l}\text { Acute inpatient, } \\
\text { OR }(99 \% \mathrm{CI})^{2}\end{array}$ & $\begin{array}{l}\text { Primary care, } \\
\text { OR }(99 \% \mathrm{Cl})^{2}\end{array}$ & $\begin{array}{c}\text { Emergency services, } \\
\text { OR }(99 \% \mathrm{CI})^{2}\end{array}$ & $\begin{array}{c}\text { Extended services, } \\
\text { OR }(99 \% \mathrm{Cl})^{2}\end{array}$ \\
\hline Health status of community & $0.91(0.81,1.02)$ & $0.72(0.46,1.10)$ & $0.70(0.46,1.07)$ & $0.82(0.51,1.30)$ & $0.83(0.50,1.38)$ \\
\hline \multicolumn{6}{|l|}{ Year } \\
\hline 2017 & Referent & Referent & Referent & Referent & Referent \\
\hline $\mathrm{N}$ & 8,594 & 8,568 & 8,569 & 8,574 & 8,508 \\
\hline
\end{tabular}

home program only, relative to hospitals that were not participating in either an ACO or medical home (Table 3). The odds of integrating behavioral health in primary care were 2.51 (99\% CI: 1.91, 3.31) times greater for hospitals that participating in an ACO and had an established medical home program, relative to hospitals that were not participating in either program.

\section{Emergency services behavioral health integration}

On average, the odds of integrating behavioral health in emergency services were 1.74 (99\% CI: 1.29, 2.34) times greater for hospitals with an established medical home program and participating in an ACO, relative to hospitals that were not participating in either (Table 3).

\section{Extended services behavioral bealth integration}

There were no significant relationships between participation in delivery system reform programs and behavioral health integration in extended service areas.

\section{Comparisons between delivery system reform programs}

The previous analysis highlights differences between delivery system reform participation and non-participation; however, our analysis also found significant differences between hospitals participating in these different programs. In terms of the breadth of behavioral health integration areas, post-hoc comparisons indicate that hospitals that were neither members of an ACO nor had an established medical home program reported integrating behavioral health into an average of 1.44 service areas, compared to 1.57 and 1.74 areas for hospitals participating in an ACO only and with an established medical home program only, respectively (Table 4). The number of integration areas for hospitals with only an established medical home program (1.74) were significantly greater than for hospitals that were only participants in an ACO (1.57). Hospitals that were members of an ACO and had an established medical home program reported behavioral health integration into 1.88 service areas, on average, which was significantly greater than hospitals that were only participants in an ACO or only had an established medical home program. Collectively, these findings provide support for hypothesis 1 , hypothesis 2 , and hypothesis 3 .

\section{Discussion}

Our analysis points to a mixed pattern of behavioral health integration across the four service areas. The most prevalent area for integration was emergency services, followed by inpatient services then primary care, while the least prevalent area for integration was extended care services (e.g., nursing homes). One explanation for this pattern is the historical focus of acute care hospitals on acute care, such as inpatient and emergency services. Vertical expansion into "upstream" (i.e., primary care) and "downstream" (i.e., extended care) service areas, in comparison, is a more recent strategy by acute care hospitals that has waxed and waned over the past 30-40 years $(39,40)$. Acute care hospitals may simply have more experience with inpatient and emergency services, and thus, may focus their efforts on integrating behavioral health into these areas. Similarly, because 
Table 4 Predicted number and predicted probabilities of behavioral integration activities

\begin{tabular}{lccccc}
\hline Variable & $\begin{array}{l}\text { Predicted number } \\
\text { of total integration } \\
\text { activities }(95 \% \mathrm{Cl})\end{array}$ & $\begin{array}{c}\text { Predicted probability } \\
\text { of acute care service } \\
\text { integration }(99 \% \mathrm{Cl})\end{array}$ & $\begin{array}{c}\text { Predicted probability } \\
\text { of primary care service } \\
\text { integration }(99 \% \mathrm{Cl})\end{array}$ & $\begin{array}{c}\text { Predicted probability } \\
\text { of emergency services } \\
\text { integration }(99 \% \mathrm{Cl})\end{array}$ & $\begin{array}{c}\text { Predicted probability } \\
\text { of extended services } \\
\text { integration }(99 \% \mathrm{Cl})\end{array}$ \\
\hline Neither & $1.44(1.36,1.51)^{2,3,4}$ & $0.46(0.42,0.50)^{2,3,4}$ & $0.36(0.32,0.39)^{3,4}$ & $0.60(0.56,0.64)^{4}$ & $0.14(0.11,0.16)$ \\
ACO only & $1.57(1.47,1.68)^{1,3,4}$ & $0.53(0.46,0.60)^{1,4}$ & $0.39(0.33,0.45)^{3,4}$ & $0.64(0.58,0.70)^{4}$ & $0.11(0.08,0.15)^{3,4}$ \\
Medical Home only & $1.74(1.65,1.83)^{1,2,4}$ & $0.54(0.49,0.59)^{1,4}$ & $0.50(0.46,0.55)^{1,2,4}$ & $0.65(0.60,0.69)^{4}$ & $0.17(0.14,0.21)^{2}$ \\
$\begin{array}{l}\text { Both ACO \& Medical } \\
\text { Home }\end{array}$ & $1.88(1.78,1.98)^{1,2,3}$ & $0.62(0.57,0.67)^{1,2,3}$ & $0.58(0.53,0.63)^{1,2,3}$ & $0.72(0.68,0.77)^{1,2,3}$ & $0.18(0.14,0.21)^{2}$ \\
\hline
\end{tabular}

${ }^{1}$, significantly different than "Neither" at $\mathrm{P}<0.01 ;{ }^{2}$, significantly different than "ACO only" at $\mathrm{P}<0.01 ;{ }^{3}$, significantly different than "Medical Home only" at $\mathrm{P}<0.01 ;{ }^{4}$, significantly different than "Both ACO \& Medical Home" at $\mathrm{P}<0.01$. ACO, accountable care organization.

inpatient and emergency services are often physically colocated, efforts to integrate behavioral health in these areas may occur in tandem and even leverage the same resources (e.g., professional staff, physical space). In contrast, primary care and extended care service areas are likely more numerous, geographically distributed, and varied in their capacity (e.g., limited staff, higher levels of turnover) to integrate behavioral health services to a similar extent.

Our findings suggest that participation in either an ACO or medical home program, by itself, is associated with more behavioral health integration. Notably, our findings related to having an established medical home program were more robust than those related to participation in an ACO. This pattern is somewhat surprising given the emphasis that ACO reimbursement mechanisms place on broad population health management across the continuum of care compared to medical home programs that often focus on primary care. One potential explanation for these differences is that ACOs are part delivery system reform and part financial reimbursement reform. If a hospital's primary motivation for pursuing ACO participation is financial (e.g., access to contracts, upside incentives), behavioral health integration may not provide a strong enough return-on-investment to significantly alter its service mix. Medical home programs, by contrast, put more direct emphasis on transforming how care is delivered. A related explanation for this pattern is the difference in what these programs entail and how they are implemented. There is considerable variation in how ACOs can be configured, governed (e.g., hospital-led, physicianled, hybrid), and the degree to which they are horizontally and vertically integrated. While it is true that there are different medical home programs (e.g., NCQA, Joint Commission, proprietary programs), most build on the same general principles, and thus, exhibit less variation than
ACOs in how they are implemented. It is also notable that hospitals participating in both programs reported greater behavioral health integration than hospitals participating in ACOs only. ACOs and medical homes, in combination, may work synergistically by aligning incentives and fostering accountability (ACOs) and creating fundamental change in how care is delivered (medical homes).

The findings of our analysis presented above should be interpreted in light of several limitations. First, our analysis was cross-sectional and we cannot make causal inferences based on our results. For example, it is plausible that hospitals decide to join an ACO or pursue a medical home program, in part, because they already have a sufficient level of integration between physical and behavioral health that enables them to be successful with these models. A second potential limitation of the analysis pertains to our measures of behavioral health integration. Accurate responses to these questions require knowledge across the entire enterprise, which may be more difficult in certain types of hospitals (e.g., large, complex systems). The responses also assume respondents from different hospitals have similar definitions of integration, which may not be the case given different degrees of integration (e.g., co-location $v s$. teambased care with shared decision making). Furthermore, it is possible the responses reflect a level of social desirability, with respondents wanting their hospitals to appear more progressive in terms of their integration activities. However, we are not aware of other data sources that are currently available that would provide population level estimates of these integration activities as well as detailed information about behavioral health integration that could tease out these nuances. Future research may be able to address these issues and validate the degree of behavioral health integration but will likely require primary data collection, 
given the data currently available.

Third, our measures of ACO and medical home participation were dichotomous indicators and did not reflect some of the nuances of participation. Moreover, given the secondary nature of our data, we were not able to validate responses as to whether hospitals were, in fact, participating in ACOs and medical homes. While our estimates of ACO participation are consistent with other studies (41), we are not aware of any sources that would enable us to make similar assessments for hospital participation in medical homes. Given the absence of such information, we consider our estimates an important contribution by providing initial estimates of how much hospitals may be associated with PCMHs. Nevertheless, future research could build on our results, for example, by validating these responses and examining whether integration, overall or for specific service areas, differs for certain types of ACOs (e.g., physician-led vs. hospital-led).

\section{Practice implications}

The findings of our study highlight several opportunities for practitioners and policy makers to improve behavioral health integration by acute care hospitals. First, integration of behavioral health into extended care areas like nursing homes, in particular, is needed by hospitals, with less than $20 \%$ of all sample hospitals reporting integration in this area. Mental health illness is one critical factor that can lead to nursing home placement (42), with one study finding that nearly $20 \%$ of newly admitted nursing home residents had a non-dementia mental health illness diagnosis (43). Moreover, nursing home patients with a mental health illness are associated with greater mortality, likelihood of hospital admission, and emergency services utilization $(44,45)$. Unfortunately, extended care was the one service area that was not significantly associated with either ACO participation or having an established medical home program. It is possible the incentives of these programs and the benefits of pursuing behavioral health integration in these settings are not sufficient to justify the costs and challenges (e.g., staffing and coordination, physical space). Thus, policy makers, regulators, and even third-party payers may need to develop more targeted efforts (e.g., enhanced reimbursement, incentives/disincentives) to support integration in these areas. For example, in the United States the largest payer of nursing home services is the Centers for Medicare and Medicaid Services (CMS). CMS has developed Nursing Home Compare, a consumer-oriented public reporting website that allows consumers to locate and compare nursing homes on key performance metrics like staffing levels and quality of care. Adding metrics like behavioral health integration to this website could incentivize hospitals (and even standalone nursing homes) to integrate these services with existing medical services.

Second, notwithstanding the results related to extended care, our findings suggest that one way to support behavioral health integration is to promote the adoption of delivery system reforms such as ACOs and medical homes by acute care hospitals. Our findings also indicate, however, that nearly two-thirds of all U.S. acute care hospitals are not participating in these programs; thus, continued efforts are needed from policy makers to stimulate participation in these programs. Findings from our analysis suggest that policy makers in particular may want to identify ways to support hospital participation in medical homes as it exhibited more robust relationships with behavioral health integration. Even so, the mixed findings with respect to whether these programs are associated behavioral health integration in different clinical areas suggest these programs are incomplete solutions, and thus, revisions to these programs may be needed or even new programs altogether that focus on behavioral health integration. Likewise, it is notable that research suggests that hospitals that are most likely to participate in these programs tend to be larger, well-resourced organizations located in urban areas $(38,41,46)$. Consequently, participation in these programs may continue to foster behavioral integration, but it may have the unintended consequence of exacerbating uneven distribution of behavioral health resources and contribute to existing disparities in behavioral health care (47-49). Policy makers and organizational decision-makers should be attentive to such potential consequences when considering the adoption and implementation of these programs.

\section{Acknowledgments}

Funding: None.

\section{Footnote}

Data Sharing Statement: Available at https://jhmhp. amegroups.com/article/view/10.21037/jhmhp-21-45/dss

Peer Review File: Available at https://jhmhp.amegroups.com/ 
article/view/10.21037/jhmhp-21-45/prf

Conflicts of Interest: Both authors have completed the ICMJE uniform disclosure form (available at https://jhmhp. amegroups.com/article/view/10.21037/jhmhp-21-45/coif). The authors have no conflicts of interest to declare.

Ethical Statement: The authors are accountable for all aspects of the work in ensuring that questions related to the accuracy or integrity of any part of the work were appropriately investigated and resolved. The study received ethical approval (determined to be Not Human Subjects Research) by the Institutional Review Board of the University of Alabama at Birmingham (Protocol \#: 300003568).

Open Access Statement: This is an Open Access article distributed in accordance with the Creative Commons Attribution-NonCommercial-NoDerivs 4.0 International License (CC BY-NC-ND 4.0), which permits the noncommercial replication and distribution of the article with the strict proviso that no changes or edits are made and the original work is properly cited (including links to both the formal publication through the relevant DOI and the license). See: https://creativecommons.org/licenses/by-nc-nd/4.0/.

\section{References}

1. Steel Z, Marnane C, Iranpour C, et al. The global prevalence of common mental disorders: a systematic review and meta-analysis 1980-2013. Int J Epidemiol 2014;43:476-93.

2. Parks J, Svendsen D, Singer P, et al. Morbidity and mortality in people with serious mental illness. Alexandria, VA: National Association of State Mental Health Program Directors (NASMHPD) Medical Directors Council, 2006;25:1-87.

3. Dickinson WP. Strategies to Support the Integration of Behavioral Health and Primary Care: What Have We Learned Thus Far? J Am Board Fam Med 2015;28 Suppl 1:S102-6.

4. Vogel ME, Kanzler KE, Aikens JE, et al. Integration of behavioral health and primary care: current knowledge and future directions. J Behav Med 2017;40:69-84.

5. McDermott KW, Elixhauser A, Sun R. Trends in hospital inpatient stays in the United States, 2005-2014. HCUP statistical brief. Available online: https://www.hcup-us. ahrq.gov/reports/statbriefs/sb225-Inpatient-US-Stays-
Trends.pdf

6. Moore BJ, Stocks C, Owens PL. Trends in emergency department visits, 2006-2014. HCUP statistical brief. Available online: https://www.hcup-us.ahrq.gov/reports/ statbriefs/sb227-Emergency-Department-Visit-Trends.pdf

7. Chakravarthy B, Tenny M, Anderson CL, et al. Analysis of mental health substance abuse-related emergency department visits from 2002 to 2008. Subst Abus 2013;34:292-7.

8. Jansen L, van Schijndel M, van Waarde J, et al. Healtheconomic outcomes in hospital patients with medicalpsychiatric comorbidity: A systematic review and metaanalysis. PLoS One 2018;13:e0194029.

9. Ader J, Stille CJ, Keller D, et al. The medical home and integrated behavioral health: advancing the policy agenda. Pediatrics 2015;135:909-17.

10. Scharf DM, Eberhart NK, Schmidt N, et al. Integrating primary care into community behavioral health settings: programs and early implementation experiences. Psychiatr Serv 2013;64:660-5.

11. Butler M, Kane RL, McAlpine D, et al. Integration of mental health/substance abuse and primary care. Database of Abstracts of Reviews of Effects (DARE): Qualityassessed Reviews. Centre for Reviews and Dissemination (UK), 2008.

12. Krupski A, West II, Scharf DM, et al. Integrating Primary Care Into Community Mental Health Centers: Impact on Utilization and Costs of Health Care. Psychiatr Serv 2016;67:1233-9.

13. Scharf DM, Eberhart NK, Hackbarth NS, et al. Evaluation of the SAMHSA Primary and Behavioral Health Care Integration (PBHCI) Grant Program: Final Report. Rand Health Q 2014;4:6.

14. Bao Y, Casalino LP, Pincus HA. Behavioral health and health care reform models: patient-centered medical home, health home, and accountable care organization. J Behav Health Serv Res 2013;40:121-32.

15. Domino ME, Wells R, Morrissey JP. Serving persons with severe mental illness in primary care-based medical homes. Psychiatr Serv 2015;66:477-83.

16. Mechanic D. Seizing opportunities under the Affordable Care Act for transforming the mental and behavioral health system. Health Aff (Millwood) 2012;31:376-82.

17. Fisher ES, McClellan MB, Bertko J, et al. Fostering accountable health care: moving forward in medicare. Health Aff (Millwood) 2009;28:w219-31.

18. Rittenhouse DR, Shortell SM, Fisher ES. Primary care and accountable care--two essential elements of delivery- 
system reform. N Engl J Med 2009;361:2301-3.

19. Baker LC, Bundorf MK, Devlin AM, et al. Hospital Ownership of Physicians: Hospital Versus Physician Perspectives. Med Care Res Rev 2018;75:88-99.

20. Bishop TF, Shortell SM, Ramsay PP, et al. Trends in hospital ownership of physician practices and the effect on processes to improve quality. Am J Manag Care 2016;22:172-6.

21. Casalino LP, November EA, Berenson RA, et al. Hospitalphysician relations: two tracks and the decline of the voluntary medical staff model. Health Aff (Millwood) 2008;27:1305-14.

22. Wang PS, Demler O, Olfson M, et al. Changing profiles of service sectors used for mental health care in the United States. Am J Psychiatry 2006;163:1187-98.

23. Fisher ES, Shortell SM. Accountable care organizations: accountable for what, to whom, and how. JAMA 2010;304:1715-6.

24. McClellan M, McKethan AN, Lewis JL, et al. A national strategy to put accountable care into practice. Health Aff (Millwood) 2010;29:982-90.

25. Shortell SM, Wu FM, Lewis VA, et al. A taxonomy of accountable care organizations for policy and practice. Health Serv Res 2014;49:1883-99.

26. Douven R, McGuire TG, McWilliams JM. Avoiding unintended incentives in ACO payment models. Health Aff (Millwood) 2015;34:143-9.

27. Roehrig C, Miller G, Lake C, et al. National health spending by medical condition, 1996-2005. Health Aff (Millwood) 2009;28:w358-67.

28. Unützer J, Patrick DL, Simon G, et al. Depressive symptoms and the cost of health services in HMO patients aged 65 years and older. A 4-year prospective study. JAMA 1997;277:1618-23.

29. Stange KC, Nutting PA, Miller WL, et al. Defining and measuring the patient-centered medical home. J Gen Intern Med 2010;25:601-12.

30. Working Party Group on Integrated Behavioral Healthcare:, Baird M, Blount A, et al. Joint principles: integrating behavioral health care into the patient-centered medical home. Ann Fam Med 2014;12:183-5.

31. Kellerman R, Kirk L. Principles of the patient-centered medical home. Am Fam Physician 2007;76:774-5.

32. Croghan TW, Brown JD. Integrating mental health treatment into the patient centered medical home. MD: Agency for Healthcare Research and Quality Rockville, 2010.

33. Edwards ST, Abrams MK, Baron RJ, et al. Structuring payment to medical homes after the affordable care act. J Gen Intern Med 2014;29:1410-3.

34. Friedberg MW, Hussey PS, Schneider EC. Primary care: a critical review of the evidence on quality and costs of health care. Health Aff (Millwood) 2010;29:766-72.

35. Phillips RL Jr, Bazemore AW. Primary care and why it matters for U.S. health system reform. Health Aff (Millwood) 2010;29:806-10.

36. American Hospital Association. Data Collection Methods. Chicago, IL: American Hospital Association, 2019.

Available online: http://www.ahadata.com/data-collectionmethods/

37. Robert Wood Johnson Foundation. About the County Health Rankings \& Roadmaps. Available online: http:// www.countyhealthrankings.org/about-project

38. Chukmaitov AS, Harless DW, Bazzoli GJ, et al. Factors associated with hospital participation in Centers for Medicare and Medicaid Services' Accountable Care Organization programs. Health Care Manage Rev 2019;44:104-14.

39. Snail TS, Robinson JC. Organizational diversification in the American hospital. Annu Rev Public Health 1998;19:417-53.

40. Starkweather DB, Carman JM. Horizontal and vertical concentrations in the evolution of hospital competition. Adv Health Econ Health Serv Res 1987;7:179-94.

41. Colla CH, Lewis VA, Tierney E, et al. Hospitals Participating In ACOs Tend To Be Large And Urban, Allowing Access To Capital And Data. Health Aff (Millwood) 2016;35:431-9.

42. Black BS, Rabins PV, German PS. Predictors of nursing home placement among elderly public housing residents. Gerontologist 1999;39:559-68.

43. Fullerton CA, McGuire TG, Feng Z, et al. Trends in mental health admissions to nursing homes, 1999-2005. Psychiatr Serv 2009;60:965-71.

44. Bartels SJ, Mueser KT, Miles KM. A comparative study of elderly patients with schizophrenia and bipolar disorder in nursing homes and the community. Schizophr Res 1997;27:181-90.

45. Forsell Y, Winblad B. Major depression in a population of demented and nondemented older people: prevalence and correlates. J Am Geriatr Soc 1998;46:27-30.

46. Rittenhouse DR, Casalino LP, Shortell SM, et al. Small and medium-size physician practices use few patientcentered medical home processes. Health Aff (Millwood) 2011;30:1575-84.

47. Andrilla CHA, Patterson DG, Garberson LA, et al. 
Geographic Variation in the Supply of Selected Behavioral Health Providers. Am J Prev Med 2018;54:S199-207.

48. Peen J, Schoevers RA, Beekman AT, et al. The current status of urban-rural differences in psychiatric disorders. Acta Psychiatr Scand 2010;121:84-93.

doi: $10.21037 / \mathrm{jhmhp}-21-45$

Cite this article as: Hearld LR, Kelly RJ. Participation in delivery system reform programs and U.S. acute care hospital integration into behavioral health. J Hosp Manag Health Policy 2022;6:15.
49. Solmi F, Dykxhoorn J, Kirkbride JB. Urban-rural differences in major mental health conditions. Solmi F, Dykxhoorn J, Kirkbride JB. Urban-rural differences in major mental health conditions. Singapore: Springer, 2017. 
Table S1 Sample characteristics by behavioral health integration areas, 2019

\begin{tabular}{|c|c|c|c|c|c|}
\hline Variable & Acute inpatient & Primary care & Emergency room & Extended care & Difference $b / t$ areas \\
\hline \multicolumn{6}{|l|}{ Organizational controls } \\
\hline Ownership & & & & & $\chi^{2}=44.4, P<0.001$ \\
\hline Private, not-for-profit, n (\%) & $1(0.26)$ & $40(10.6)$ & $247(65.2)$ & $91(24.0)$ & \\
\hline Public, not-for-profit, n (\%) & $22(1.4)$ & $85(5.3)$ & $1,089(67.3)$ & $423(26.1)$ & \\
\hline For-profit, n (\%) & $6(3.4)$ & $2(1.1)$ & $143(80.8)$ & $26(24.8)$ & \\
\hline System affiliation & & & & & $\chi^{2}=20.6, P<0.001$ \\
\hline Member of system, n (\%) & $22(1.4)$ & $73(4.5)$ & $1,120(69.6)$ & $394(24.5)$ & \\
\hline Independent, n (\%) & $7(1.2)$ & $54(9.5)$ & $359(63.4)$ & $146(25.8)$ & \\
\hline Teaching status & & & & & $\chi^{2}=19.6, P<0.001$ \\
\hline Teaching hospital, n (\%) & $14(1.2)$ & $51(4.2)$ & $819(67.5)$ & $330(27.2)$ & \\
\hline Non-teaching hospital, n (\%) & $15(1.6)$ & $76(7.9)$ & $660(68.7)$ & $210(21.9)$ & \\
\hline Contract management & & & & & $\chi^{2}=2.7, P=0.10$ \\
\hline Contract managed, n (\%) & $0(0.0)$ & $9(5.0)$ & $117(64.6)$ & $55(30.4)$ & \\
\hline Not contract managed, n (\%) & $29(1.5)$ & $118(5.9)$ & $1,362(68.3)$ & $485(24.3)$ & \\
\hline Clinically Integrated Network & & & & & $\chi^{2}=18.0, P<0.001$ \\
\hline Clinically Integrated Network, n (\%) & $15(1.2)$ & $54(4.5)$ & $803(66.6)$ & $333(27.6)$ & \\
\hline Not a Clinically Integrated Network, n (\%) & $14(1.4)$ & $73(7.5)$ & $676(69.7)$ & $207(21.3)$ & \\
\hline$\#$ of beds & & & & & $\chi^{2}=69.4, P<0.001$ \\
\hline 6-99, n (\%) & $10(1.2)$ & $82(9.7)$ & $570(67.6)$ & $181(21.5)$ & \\
\hline 100-299, n (\%) & $13(1.7)$ & $33(4.3)$ & $546(70.4)$ & $184(23.7)$ & \\
\hline 300-499, n (\%) & $6(1.9)$ & $8(2.5)$ & $220(69.6)$ & $82(26.0)$ & \\
\hline 500 or more, $\mathrm{n}(\%)$ & $0(0.0)$ & $4(1.7)$ & $143(59.6)$ & $93(38.8)$ & \\
\hline Sole community provider status & & & & & $\chi^{2}=1.6, P=0.67$ \\
\hline Sole community Provider, n (\%) & $2(1.3)$ & $7(4.7)$ & $108(72.5)$ & $32(21.5)$ & \\
\hline Not sole community provider, n (\%) & $27(1.3)$ & $120(5.9)$ & $1,371(67.7)$ & $508(25.1)$ & \\
\hline$\%$ of revenue from capitation, mean (SD) & $0(0.0)$ & $2.5(9.4)$ & $1.8(8.5)$ & $3.3(14.8)$ & $\mathrm{F}=2.8, \mathrm{P}=0.04$ \\
\hline \multicolumn{6}{|l|}{ Community controls } \\
\hline Geographic location & & & & & $\chi^{2}=28.9, P<0.001$ \\
\hline Rural hospital, n (\%) & $2(0.7)$ & $27(9.9)$ & $176(64.5)$ & $68(24.9)$ & \\
\hline Suburban, n (\%) & $9(2.1)$ & $39(9.2)$ & $286(67.1)$ & $92(21.6)$ & \\
\hline Urban hospital, n (\%) & $18(1.2)$ & $61(4.1)$ & $1,017(68.9)$ & $380(25.8)$ & \\
\hline $\begin{array}{l}\text { Medicare managed care penetration, } \\
\text { mean }(S D)\end{array}$ & $34.9(16.4)$ & $28.1(14.3)$ & $30.6(13.6)$ & $31.5(14.9)$ & $\mathrm{F}=2.9, \mathrm{P}=0.04$ \\
\hline Percent minority, mean (SD) & $18.4(14.4)$ & $14.4(14.3)$ & $19.7(15.2)$ & $18.9(14.6)$ & $\mathrm{F}=4.9, \mathrm{P}=0.002$ \\
\hline Percent over 65, mean (SD) & $17.8(3.7)$ & $18.6(4.5)$ & $17.1(4.1)$ & $17.2(4.0)$ & $F=5.8, P<0.001$ \\
\hline $\begin{array}{l}\text { Percent below federal poverty level, } \\
\text { mean (SD) }\end{array}$ & $14.8(5.5)$ & $13.1(4.8)$ & $13.5(5.0)$ & $13.0(4.4)$ & $\mathrm{F}=2.7, \mathrm{P}=0.05$ \\
\hline Herfindahl-Hirschman index, mean (SD) & $0.55(0.34)$ & $0.70(0.31)$ & $0.58(0.35)$ & $0.58(0.35)$ & $F=4.6, P=0.003$ \\
\hline Mental health professional shortage area & & & & & $\chi^{2}=12.5, P=0.051$ \\
\hline County not MH HPSA, n (\%) & $3(2.1)$ & $9(6.2)$ & $101(69.7)$ & $32(22.1)$ & \\
\hline Partial county is MH HPSA, $n(\%)$ & $12(1.6)$ & $56(7.6)$ & $503(68.5)$ & $163(22.2)$ & \\
\hline Whole county is MH HPSA, $n(\%)$ & $14(1.1)$ & $62(4.8)$ & $875(67.5)$ & $345(26.6)$ & \\
\hline Health status of community & $0.01(0.43)$ & $-0.13(0.45)$ & $-0.05(0.44)$ & $-0.09(0.42)$ & $F=2.5, P=0.06$ \\
\hline $\mathrm{N}$ & 4,460 & & & 4,364 & \\
\hline
\end{tabular}

Statistically significant difference at $\mathrm{P}<0.05$ between areas of integration. MH HPSA, mental health professional shortage area. 
Table S2 Sample characteristics by delivery system reform program, 2019

\begin{tabular}{|c|c|c|c|c|c|}
\hline Variable & None & ACO only & $\begin{array}{l}\text { Medical } \\
\text { home only }\end{array}$ & $\begin{array}{l}\text { Both ACO \& } \\
\text { medical home }\end{array}$ & $\begin{array}{l}\text { Difference b/t } \\
\text { programs }^{1}\end{array}$ \\
\hline \multicolumn{6}{|l|}{ Organizational controls } \\
\hline Ownership & & & & & $\chi^{2}=627.0, P<0.001$ \\
\hline Private, not-for-profit, n (\%) & $751(78.5)$ & $26(2.7)$ & $126(13.2)$ & $54(5.6)$ & \\
\hline Public, not-for-profit, n (\%) & $1,300(47.4)$ & $213(7.8)$ & $603(22.0)$ & $629(22.9)$ & \\
\hline For-profit, n (\%) & $608(91.6)$ & $24(3.6)$ & $24(3.6)$ & $8(1.2)$ & \\
\hline System affiliation & & & & & $\chi^{2}=437.4, P<0.001$ \\
\hline Member of system, n (\%) & $1,449(50.6)$ & $231(8.1)$ & $549(19.2)$ & $637(22.2)$ & \\
\hline Independent, n (\%) & $1,210(80.7)$ & $32(2.1)$ & $204(13.6)$ & $54(3.6)$ & \\
\hline Teaching status & & & & & $\chi^{2}=256.9, P<0.001$ \\
\hline Teaching hospital, n (\%) & $933(48.4)$ & $148(7.7)$ & $389(20.2)$ & $457(23.7)$ & \\
\hline Non-teaching hospital, n (\%) & $1,726(70.8)$ & $115(4.7)$ & $364(14.9)$ & $234(9.6)$ & \\
\hline Contract management & & & & & $\chi^{2}=3.8, P=0.28$ \\
\hline Contract managed, n (\%) & $205(63.1)$ & $18(5.5)$ & $62(19.1)$ & $40(12.3)$ & \\
\hline Not contract managed, n (\%) & $2,454(60.7)$ & $245(6.1)$ & $691(17.1)$ & $651(16.1)$ & \\
\hline Clinically integrated network & & & & & $\chi^{2}=983.24, P<0.001$ \\
\hline Clinically integrated network, n (\%) & $289(19.1)$ & $152(10.0)$ & $543(35.8)$ & $533(35.1)$ & \\
\hline Not a clinically integrated network, $\mathrm{n}(\%)$ & $2,370(83.2)$ & $111(3.9)$ & $210(7.4)$ & $158(5.6)$ & \\
\hline \# of beds & & & & & $\chi^{2}=338.6, P<0.001$ \\
\hline $6-99, \mathrm{n}(\%)$ & $1,564(70.6)$ & $106(4.8)$ & $337(15.2)$ & $209(9.4)$ & \\
\hline 100-299, n (\%) & $808(57.8)$ & $74(5.3)$ & $253(18.1)$ & $264(18.9)$ & \\
\hline 300-499, n (\%) & $208(45.0)$ & 49 (10.6) & $99(21.4)$ & $106(22.9)$ & \\
\hline 500 or more, $\mathrm{n}(\%)$ & $79(27.3)$ & $34(11.8)$ & $64(22.2)$ & $112(38.8)$ & \\
\hline \multicolumn{6}{|l|}{ Sole community provider status } \\
\hline Sole community provider, $\mathrm{n}(\%)$ & $208(68.9)$ & $12(4.0)$ & $58(19.2)$ & $24(8.0)$ & $\chi^{2}=19.1, P<0.001$ \\
\hline Not sole community provider, $\mathrm{n}(\%)$ & $2,451(60.3)$ & $251(6.2)$ & $695(17.1)$ & $667(16.4)$ & \\
\hline$\%$ of revenue from capitation, mean (SD) & $0.5(3.5)$ & $2.7(6.8)$ & $3.9(15.7)$ & $1.1(5.3)$ & $F=24.5, P<0.001$ \\
\hline \multicolumn{6}{|l|}{ Community controls } \\
\hline Geographic location & & & & & $\chi^{2}=222.9, P<0.001$ \\
\hline Rural hospital, n (\%) & $618(77.2)$ & $27(3.4)$ & $112(14.0)$ & $44(5.5)$ & \\
\hline Suburban, n (\%) & $688(68.1)$ & $46(4.6)$ & $176(17.4)$ & $101(10.0)$ & \\
\hline Urban hospital, n (\%) & $1,353(53.0)$ & $190(7.4)$ & $465(18.2)$ & $546(21.4)$ & \\
\hline $\begin{array}{l}\text { Medicare managed care penetration, } \\
\text { mean (SD) }\end{array}$ & $28.7(15.6)$ & $32.8(12.3)$ & $31.3(14.2)$ & $32.4(11.4)$ & $F=18.7, P<0.001$ \\
\hline Percent minority, mean (SD) & $18.6(16.3)$ & $18.2(14.3)$ & $17.5(14.5)$ & $21.5(15.3)$ & $F=8.5, P<0.001$ \\
\hline Percent over 65 , mean (SD) & $18.2(4.7)$ & $17.0(3.8)$ & $18.0(4.2)$ & $16.4(3.9)$ & $\mathrm{F}=31.7, \mathrm{P}<0.001$ \\
\hline $\begin{array}{l}\text { Percent below federal poverty level, } \\
\text { mean (SD) }\end{array}$ & $14.9(5.6)$ & $13.7(4.9)$ & $13.7(4.8)$ & $12.3(4.4)$ & $\mathrm{F}=48.1, \mathrm{P}<0.001$ \\
\hline Herfindahl-Hirschman Index, mean (SD) & $0.67(0.34)$ & $0.57(0.34)$ & $0.62(0.35)$ & $0.52(0.33)$ & $F=35.6, P<0.001$ \\
\hline Mental Health Professional Shortage Area & & & & & $\chi^{2}=200.1, P<0.001$ \\
\hline County not MH HPSA, n (\%) & $115(48.5)$ & $15(6.3)$ & $50(21.1)$ & $57(24.1)$ & \\
\hline Partial county is MH HPSA, $n(\%)$ & $1,342(71.9)$ & $81(4.3)$ & $284(15.2)$ & $160(8.6)$ & \\
\hline Whole county is HPSA hospital, $\mathrm{n}(\%)$ & $1,200(53.1)$ & $167(7.4)$ & $419(18.5)$ & $474(21.0)$ & \\
\hline Health status of community & $0.05(0.48)$ & $-0.002(0.42)$ & $-0.05(0.43)$ & $-0.13(0.42)$ & $F=30.9, P<0.001$ \\
\hline $\mathrm{N}$ & 4,460 & & & 4,364 & \\
\hline
\end{tabular}

Statistically significant difference at $\mathrm{P}<0.05$ between areas of integration. MH HPSA, mental health professional shortage area. 